\title{
Research on Post Investment Evaluation of Distribution Network Infrastructure Project Adapting to Transmission and Distribution Price Reform
}

\author{
Linjun Zeng ${ }^{1 *}$, Yan Zeng ${ }^{1}$, Dan Wang ${ }^{1}$, Pan Chen ${ }^{2}$, Xin Hong ${ }^{3}$, Juan Huang ${ }^{4}$, Hongwei $\mathrm{Su}^{5}$ \\ ${ }^{1}$ State Grid Shiyan Power Supply Company, Shiyan, Hubei Province, 442000, China \\ ${ }^{2}$ State Grid Yunxi County Power Supply Company, Yunxi, Hubei Province, 442699, China \\ ${ }^{3}$ State Grid Yunxian power supply company, Yunxian, Hubei Province, 442599, China \\ ${ }^{4}$ State Power Investment Group Jiangxi Electric Power Co., Ltd, Nanchang, Jiangxi Province, 330096, China \\ ${ }^{5}$ Hubei Anyuan safety and Environmental Protection Technology Co., Ltd, Wuhan, Hubei Province, 430040, China
}

\begin{abstract}
Under the background of the continuous promotion of the current transmission and distribution price reform, the company's investment strategy is constantly inclined to the distribution network, so it is more important to evaluate the implementation process and effect of its investment. Therefore, on the basis of the current distribution network post evaluation work, it is urgent to adjust the project investment post evaluation index system adaptively, and strengthen its application in investment management, so as to give play to its greater value in the company's investment lean management. For this reason, combined with the requirements of the current transmission and distribution price reform, this paper puts forward two suggestions for the current post evaluation work: first, to adapt to the transmission and distribution price reform, it is suggested to optimize the existing indicators and improve the adaptability of post evaluation work; second, it is suggested to strengthen the application of post evaluation results. Through the optimization of the above two points, the closed-loop investment management of distribution network project is formed, and the efficiency of investment management is improved.
\end{abstract}

\section{Research background}

As an important part of the back-end of investment management, the post evaluation of power grid infrastructure project plays an important role in the backend decision-making of investment management. Although the current post investment evaluation work has a relatively mature evaluation index system, with the continuous promotion of the reform of transmission and distribution price, it puts forward higher requirements for the accuracy of the investment execution process of power grid infrastructure projects. How to better adapt to the requirements of transmission and distribution price reform and better assist the company's investment strategy is the focus of post investment evaluation work: first, the transmission and distribution electricity price is cleared and approved once every three years. In order to meet the requirements of the transfer rate, the future investment strategy is inclined to the distribution network with shorter construction period and faster transfer efficiency. With the increasing proportion of the distribution network investment, the evaluation of its distribution network investment implementation is particularly important. Therefore, it is urgent to adjust the evaluation index system after investment; second, in order to adapt to the reform of transmission and distribution price, it is urgent to strengthen the application of post investment evaluation results of power grid infrastructure projects, so as to form a closed-loop investment management and improve the overall investment management efficiency.

\section{Research objectives}

This project takes the post evaluation of distribution network as the research object, with the goal of making the post evaluation of investment adapt to the reform of transmission and distribution electricity price, mainly carries out two aspects of research: one is to optimize the existing index system based on the current post evaluation index system, aiming at improving the efficiency of investment transfer and strengthening process monitoring; the other is to verify the correlation between investment and transmission and distribution electricity price In order to give full play to the role of post evaluation in the investment management of distribution network projects and the realization of the company's business objectives under the background of power transmission and distribution price reform. 


\section{Optimization of existing index system for post investment evaluation of distribution network projects}

The current post-assessment of investment in the distribution network is based on the county area. This chapter sorts out the current transmission and distribution price index system of the current distribution network, and combines the key parameters of the transmission and distribution price verification to increase the adaptability of the index system. The specific content is as follows:

\subsection{Post investment evaluation index system of existing distribution network}

The existing evaluation index system for distribution network investment is mainly evaluated from 43 indicators in six aspects: project decision-making, project implementation, grid indicators, input and output, social benefits and economic benefits, as shown in the following table:

Table 1. Post evaluation index system of existing distribution network

\begin{tabular}{|c|c|c|}
\hline First level indicators & Secondary indicators & Company \\
\hline \multirow{4}{*}{ Project decision making } & Planning project responsiveness & $\%$ \\
\hline & Feasibility study agreement rate & $\%$ \\
\hline & Approval completion rate & $\%$ \\
\hline & Initial agreement rate & $\%$ \\
\hline \multirow{6}{*}{ Project implementation } & On schedule completion rate & $\%$ \\
\hline & Engineering qualification rate & $\%$ \\
\hline & Completion rate of safety objectives & $\%$ \\
\hline & Investment deviation rate & $\%$ \\
\hline & Design change rate & $\%$ \\
\hline & Completion rate of completion acceptance & $\%$ \\
\hline \multirow{18}{*}{ Power grid indicators } & Per household distribution transformer capacity & KVA/household \\
\hline & Proportion of overhead lines with section less than $70 \mathrm{~mm}^{2}$ & $\%$ \\
\hline & $\begin{array}{l}\text { Proportion of cable lines with cross section less than } \\
185 \mathrm{~mm}^{2}\end{array}$ & $\%$ \\
\hline & Capacity load ratio of distribution transformer & - \\
\hline & Interconnection rate of $10 \mathrm{kV}$ line & $\%$ \\
\hline & "N-1" passing rate of $10 \mathrm{kV}$ line & $\%$ \\
\hline & Average power supply radius of line & $\%$ \\
\hline & Average line load rate & $\%$ \\
\hline & Average load rate of distribution transformer & $\%$ \\
\hline & Comprehensive line loss rate of $10 \mathrm{kV}$ and below & $\%$ \\
\hline & Proportion of old lines & $\%$ \\
\hline & Proportion of old distribution transformer & $\%$ \\
\hline & Proportion of high loss distribution transformer & $\%$ \\
\hline & Smart meter coverage & $\%$ \\
\hline & Distribution automation coverage & $\%$ \\
\hline & Proportion of low voltage households & $\%$ \\
\hline & Power supply reliability & $\%$ \\
\hline & Comprehensive voltage qualification rate & $\%$ \\
\hline \multirow{6}{*}{ Input and output } & $\begin{array}{l}\text { Unit investment to solve the number of low voltage } \\
\text { households }\end{array}$ & Household/10000 yuan \\
\hline & $\begin{array}{l}\text { Marginal investment in power transmission and } \\
\text { distribution }\end{array}$ & $10000 \mathrm{kwh} / 10000$ yuan \\
\hline & Unit investment increase supply load & $10000 \mathrm{~kW} / 10000$ yuan \\
\hline & Unit investment increase sales of electricity & $10000 \mathrm{kwh} / 10000$ yuan \\
\hline & $\begin{array}{l}\text { Unit investment to solve the number of heavy overload } \\
\text { distribution transformer }\end{array}$ & Set/10000 yuan \\
\hline & Number of heavy overload lines solved per unit investment & Item/10000 yuan \\
\hline
\end{tabular}




\begin{tabular}{ccc}
\hline & \multicolumn{1}{c}{$\begin{array}{c}\text { The number of new interconnection lines per unit } \\
\text { investment }\end{array}$} & Item/10000 yuan \\
\cline { 2 - 3 } & New unit investment meets the number of lines N-1 & Item/10000 yuan \\
\cline { 2 - 3 } & $\begin{array}{c}\text { Unit investment to solve the number of high loss } \\
\text { distribution transformers }\end{array}$ & Set/10000 yuan \\
\cline { 2 - 3 } & $\begin{array}{c}\text { New unit investment to realize distribution automation } 10 \\
\mathrm{kV} \text { line }\end{array}$ & Item/10000 yuan \\
\hline \multirow{2}{*}{ Social benefits } & Average annual growth rate of GDP & Person \\
\hline \multirow{2}{*}{ Economic benefits } & Investment promotes employment & Year \\
\cline { 2 - 3 } & Internal rate of return on total investment & Yuan $/ \mathrm{kWh}$ \\
\hline
\end{tabular}

\subsection{Optimization of post investment evaluation index system}

According to the verification principle of transmission and distribution electricity price, the completion of the approved investment in the next three years has an important impact on the transmission and distribution electricity price level in the next regulatory cycle. Therefore, whether the project is included in the scope of price verification, the proportion of effective assets formed by the actual investment, the parameters of the approved line loss and relevant operation and maintenance rates, and the growth of electricity after investment should constitute the important contents of the project post evaluation. The specific optimization contents are as follows:

\section{(1) Planning decision}

In the planning decision-making stage, the index should be increased from two aspects of planning coordination and planning level.

In terms of planning coordination, the index of "whether to include effective investment" is added. Under the background of transmission and distribution price reform, whether the project investment can be included in the effective investment scope in the verification of transmission and distribution price has a significant impact on the verification of transmission and distribution price. At present, the connection between distribution network investment and planning is not strong, so it is necessary to consider whether the project investment and construction can be included in the scope of effective assets. Therefore, this index should be added.

With the promulgation of the notice on strengthening and standardizing the investment management of power grid planning issued by the national development and Reform Commission and the Energy Bureau, the future emphasis on "strengthening the overall coordination and implementation of power grid planning, standardizing the investment management of power grid projects included in the planning, and strengthening the analysis and evaluation of power grid planning and investment projects" means that the planning and investment should be coordinated, and the two should be rigidly linked. This measure also laid the institutional foundation for the project to be included in the scope of effective investment.

In terms of planning level, the index of "accuracy of electricity / load forecasting" is added. The accuracy of electricity / load growth forecast for the projects with load growth has a significant impact on the verification of transmission and distribution price. The realization of permitted income in the future is essentially dependent on the growth of electricity/load. If the actual forecasted electricity growth is less than expected, it means that the permitted income of the grid company will not be realized as expected, which will affect the realization of the company's business objectives.

\section{(2) Operation after commissioning}

When the transmission and distribution electricity price is checked, the line loss rate and the operation and maintenance fee rate have clear upper limit requirements. If the actual line loss and operation and maintenance fee exceed the approved upper limit, they will not be included in the scope of relevant price checking. Therefore, the line loss situation and the occurrence of operation and maintenance fee during the actual operation are evaluated to provide control standards for the actual operation of similar projects. In view of this, it is suggested to add "the deviation between the actual line loss rate and the predicted approved line loss rate" and "the deviation between the actual operation and maintenance cost in the investment ratio and the approved ratio" in the post investment evaluation of the project.

\section{(3) Economic benefits}

In terms of economic benefits, in addition to the conventional "internal rate of return of total investment, payback period of investment, cost per unit of power 
transmission and distribution", the indicators of "difference comparison between the actual indicators and the indicators in the feasibility study stage, the ratio of forming effective assets, the growth rate of increased power supply and sales / maximum load" are added.

The conventional post evaluation index of project economic benefit has very mature financial index and calculation method. In order to evaluate the actual economic benefit of the project, the analysis dimension is added to this part of index, and the actual financial index is compared with the feasibility study prediction index to analyze its deviation. Among them, for the investment projects that meet the load growth, evaluate whether the load growth meets the expectation.

Since the completion of project investment is directly related to the verification of transmission and distribution electricity price, increasing the "proportion of investment forming effective assets" can evaluate the allocation efficiency of investment resources on the one hand, and

Table 2. Evaluation indicators after adapting to the new distribution network

\begin{tabular}{|c|c|}
\hline First level indicators & Secondary indicators \\
\hline \multirow{2}{*}{ Planning decision } & Whether to include effective investment \\
\hline & Accuracy of electricity / load forecasting \\
\hline \multirow{2}{*}{ Operation after commissioning } & Deviation between actual line loss rate and predicted approved line loss rate \\
\hline & $\begin{array}{c}\text { Deviation between the actual operation and maintenance cost to the } \\
\text { investment ratio and the approved ratio }\end{array}$ \\
\hline \multirow{3}{*}{ Economic benefits } & $\begin{array}{l}\text { The actual financial indicators are compared with the forecast indicators of } \\
\text { the feasibility study }\end{array}$ \\
\hline & Is the load growth up to expectations \\
\hline & Proportion of effective assets formed by investment \\
\hline \multirow[b]{2}{*}{ Social benefits } & Customer service satisfaction \\
\hline & $\begin{array}{l}\text { Quantitative analysis of distribution network investment on carbon emission } \\
\text { reduction }\end{array}$ \\
\hline
\end{tabular}

evaluate whether the transfer of capital meets the verification requirements of transmission and distribution electricity price transfer rate on the other hand.

\section{(4) Social results}

In terms of social benefits, in addition to the conventional investment driving GDP and employment growth, the in the current transmission and distribution price reform process of power grid companies. Therefore, it is necessary to consider increasing customer service satisfaction; in the current "carbon neutral" and "carbon peak" background, the quantitative role of distribution network investment in carbon emission reduction and other indicators.

According to the above analysis, the new post evaluation indicators are summarized as follows: proportion of market-oriented business is also increasing

\section{Optimization of existing index system for post investment evaluation of distribution network projects}

On the basis of the optimization of the above index system, combined with the current post evaluation results, the application scenarios of post evaluation are proposed to enhance the role of post evaluation in project investment management and transmission and distribution price verification.

\section{(1) Post evaluation of online investment}

Under the current company's "digital, online" initiative, the quantitative calculation and analysis of indicators in the post evaluation work can consider the conditions of the current data online collection, design the calculation logic and function of indicators online, and realize the automatic calculation of various indicators of each county company (project). The automatic measurement of post evaluation indexes can not only improve the work efficiency of post evaluation, but also make the online post evaluation results more flexible in horizontal and vertical comparison, and provide the possibility for multi scene application analysis.

\section{(2) Strengthen the closed loop management of distribution network project investment}

Based on the multi-dimensional attributes of county / project, the post investment evaluation results are analyzed and refined to form clear investment decisionmaking reference suggestions, which can provide support for subsequent investment decisions of similar projects. According to the closed-loop management process of "project planning - planning - implementation completion - evaluation - analysis - law refining - auxiliary investment", project investment management plays a role of closed-loop management and control, and improves the overall lean management level of distribution network project investment. 
(3) Accurate allocation of auxiliary distribution network investment

According to the post evaluation results of each county (project), the status quo of power grid, historical inputoutput efficiency, economic benefit and social benefit of each county are horizontally compared and analyzed, and the status quo coefficient and comprehensive performance coefficient of power grid are synthesized. Combined with the reported investment demand of each county, the reference basis for accurate allocation of investment resources of municipal companies is provided.

\section{(4) Integration of post evaluation and investment execution process evaluation}

During the whole process of distribution network project planning to project closing, more detailed evaluation indexes can be designed for the implementation process, so as to avoid any deviation in any link, resulting in the deviation of distribution network investment, and thus affecting the efficiency of capital transfer. After the implementation process of post evaluation is refined, the indicators are applied to the evaluation of the implementation process of distribution network investment, that is, the content of the evaluation of the implementation process in the post evaluation is moved forward to support the daily investment management. The evaluation results of the daily investment implementation process can also form a part of the post evaluation work, which improves the integration of daily investment implementation management and post evaluation work, and strengthens its application in investment management effect.

\section{Conclusion}

Based on the current post evaluation of distribution network investment, combined with the requirements of the current transmission and distribution price reform, this paper puts forward two suggestions: first, to adapt to the transmission and distribution price reform, it is suggested to optimize the existing indicators and improve the adaptability of post evaluation; second, according to the current post evaluation results, it puts forward several aspects of application, such as promoting the online post evaluation work, strengthening the application of post evaluation results, effectively promoting the project closed-loop control, assisting the accurate allocation of distribution network investment, and strengthening the integration with daily investment implementation management. Through the above two suggestions, we hope to improve the value of post evaluation in the realization of the company's business objectives under the background of the current transmission and distribution price reform.

\section{References}

1. Yuan, A. Wang, K.D. (2019) Analysis of precise investment optimization strategy based on distribution network infrastructure project library. Electricity and Energy.
2. Xue, B.X. Dong, W.L. Shang, X.H. (2019) Process and method of county distribution network project post evaluation. Innovation and Application of Science and Technology.

3. Wu, Z. Cui, W.T. Long, Y. (2019) Post evaluation of distribution network investment effect and analysis of investment rationality. Journal of Power System and Automation. 